\title{
How the Earth remembers and forgets ${ }^{1}$
}

\section{Bronislaw Szerszynski, Lancaster University bron@lancaster.ac.uk}

to appear in Adam Bobbette and Amy Donovan (eds) (2018), Political Geology: Active Stratigraphies and the Making of Life, London: Palgrave Macmillan

\begin{abstract}
:
In this chapter I argue that we can start to extend political ideas to other entities within the Earth through deploying an intermediary concept such as 'memory'. In the domain of human politics, there has been much attention to the role of collective memory in the politics of recognition and justice but also the role that active forgetting can play in creating the conditions for progressive social change. What about the politics of the Earth? Natural scientists sometimes us the word 'memory' to describe biological or even geophysical process: they talk of 'climate memory', or 'ecological memory', or materials as having 'shape memory'. But what would happen if we took such usages seriously, and applied the idea of memory to a complex entity like a planet? How could the Earth be said to remember and to forget? What memory systems has the Earth evolved in its 4.5 billion-year 'geostory'? And if the Earth is indeed entering 'the Anthropocene', a new geological epoch in which humans are the determining geological force, how might the Anthropocene be inserting itself into the memory systems of the Earth? Might thinking of the Earth as something that remembers and forgets change the way that we think about this thing we call the Anthropocene, what it is and what it means?
\end{abstract}

Index words:

memory (hypermnesia, hypomnesia), forgetting, noise (white, black, pink), fluids, solids, Nietzsche, Deleuze, mnemotechnics (= exteriorisation = transduction of memory) 
In the spirit of continuing and radicalising the Copernican project of displacing the human from the centre of things, there have been a number of attempts in recent decades to extend ideas of politics to the Earth itself. Most of these attempts can be said to have fallen into what Quentin Meillassoux criticises as 'correlationism', 'the idea according to which we only ever have access to the correlation between thinking and being, and never to either term considered apart from the other' (Meillassoux, 2008: 5). A correlationist position on the relation between the political and the planetary would be to say that, even if we can extend politics away from the human to embrace the planetary preconditions for human's political agency (Grosz et al., 2017) then human subjectivity must somewhere be part of the chain. Even Bruno Latour's 'Parliament of things' seems to need humans to represent the 'thingsin-themselves' (Latour, 1993). But can we go further? If we define the political as that specific mode of existence characterised by what Hannah Arendt (1958) called plurality and natality, ${ }^{2}$ can we speak of a politics of the Earth in which humans and human subjectivity are not central - and sometimes even wholly absent? Perhaps counterintuitively, I will suggest that we can get further in such a task if we attempt to extend not one but two concepts beyond their usual anthropocentric boundaries. In this chapter I will thus explore a triangular relation: amongst the political, Earth processes and memory.

There have been many debates recently about the importance for political processes of memory - particularly collective memory. Generally, the argument has been that memory plays an important role in struggles for justice, and that organised forgetting is an ideological strategy used by the powerful to suppress historical claims against injustice and dispossession. However, as we shall see, there have also been counterarguments that memory can sometimes play a regressive role, and that forms of forgetting can be an important precondition for progressive politics. In what follows I will relate these debates to the more-than-human, arguing not only that we can extend the debates about politics and memory to the geophysical realm, but also that a planetary understanding of memory can perhaps help us better understand its role in human society.

In a recent debate about how memory studies can respond to the new context of the Anthropocene - the proposed new geological epoch in which humans are the determining geological force (Crutzen and Stoermer, 2000) - Richard Crownshaw (2014: 175) argues that 'memory studies need to adopt a posthumanist stance, otherwise it will be circumscribed by the normative theorization of memory's symbolic reconstitution of human life and human worlds'. Michael Rothberg (2017: 514) similarly suggests that 'a radically non-anthropocentric multidirectional memory would need to move off the grid of human(ist) comparison and ethics'. However, Rothberg (2017: 515) goes on to suggest that he is 'not yet ready to give up the [human] subject of memory and political responsibility', suggesting that there are ethical as well as epistemological reasons for remaining within the bounds of correlationism. Can we extend concepts of memory and politics beyond the humanist subject, while still retaining the power of these ideas to do important critical work?

I will explore this question through placing the event of the Anthropocene in the context of how the Earth can be said to remember and to forget. What memory systems has the Earth evolved in what Bruno Latour calls its 4.5 billion-year 'geostory'? In the context of this story, is the Anthropocene to be thought of as just another layer, inserted into the 'rock memory' of the Earth? Or does it actually change the Earth's powers of remembering and forgetting? Once informed by an awareness of the relationship between memory and politics, might thinking of the Earth as something that remembers and forgets change the way that we think about this thing we call the Anthropocene, what it is and what it means?

\section{Stretching memory}

Let me first sketch what I think are the necessary characteristics of a concept of memory that might be adequate to the task of embracing Earth processes. Let us undergo a theoretical 'memory test' a test of our conception of memory, to see how suited it is for our purpose.

Firstly, we need to find a way of talking about memory in a way that easily crosses any imagined boundary between the ideational (semiotic) and the material (physical), the living and the 
non-living and so on. It will not be enough simply to use memory metaphorically, extending by analogy from what we understand about human and more generally animal memory to the wider material world, thereby weakening the power of the concept of memory to do useful intellectual and political work. Instead, let us try to think of human memory as just a specific example of a wider phenomenon. Saying that some entity or process 'exhibits memory' need not commit us to regarding it as a subject, as having mind or consciousness, or even as being a unified, bounded entity; it may be that conscious, sentient, bounded living things that are aware of themselves as a subject are merely one kind of thing that can remember and forget.

Secondly, any deployment of the concept of memory needs to take account of the different forms that memory can take. Memory can be weak or strong in different ways - duration, resolution, recallability, and so on - and also have different qualitative characters. With human memory, we can identify some major distinctions between classes of memory process that are likely to be useful when looking beyond the human. One class involves what Edmund Husserl (1991) called 'primary retention', the immediate awareness of the unfolding of time in the present experience of duration, change and motion. In this class would belong what Henri Bergson (1959), and later Maurice Merleau-Ponty (1962), theorised as 'habitual body memory' - the slow, cumulative 'sedimentation' through repetition which builds the depth of the body's often unconscious experience of its milieu and of its own possibilities of action. By contrast, Husserl's 'secondary retention' involve cognition and imagination about more distant moments in time; here belongs what Bergson calls 'recollective memory', and contemporary psychologists 'episodic memory', where past events that happened at a particular place and time are 'recalled', often in less embodied and more representational and imagistic modes; here perhaps also belongs 'working memory', where selected information is selected and temporarily held to be used in complex cognitive tasks. If we generalise memory beyond the human, and beyond the living, then it is likely that these categories of memory will have to be wildly modified; but we can be pretty sure that some comparable set of distinctions will have to be made.

Thirdly, memory is in some sense an autorelation. As Gilles Deleuze puts it, following Immanuel Kant, ' $[\mathrm{m}]$ emory is the real name of the relation to oneself, or the affect on self by self' (Deleuze, 1988: 107). So memory is something topological, about the shape, in some sense, of the entity or assemblage that is said to have memory, how it is temporally folded, made to affect and be affected by itself across time. Memory is thus an aspect of 'the shape of time' (Kubler, 1962) - time, that is, that is understood not as a universal background or container for events but as generated by the specific ways that different entities come into existence, evolve and endure.

Fourthly, memory also includes forgetting. But forgetting is not just privative, the lack of memory. Just as only living things can die (and indeed certain kinds of death are only available to certain kinds of living things), only things that can remember can forget, in any interesting sense. Forgetting is an active process, a capacity, a skill. And as we will see the creation of specific kinds of memory can require forgetting, selection, erasure.

Fifthly, if memory is about autoaffection, as Deleuze puts it, at least some forms of memory have to be active and constitutive, affecting how something is able to react to its environment. And here again forgetting may be as important as remembering for the ability of an entity to act. As well as hypomnesia - forgetting, or under-remembering - there is hypermnesia, over-remembering, of which Nietzsche accused the ancient Greeks. ${ }^{3}$ In order to act, the individual has to overcome the stifling nature of history by recovering the powers of the pre-historical animal to forget - to develop a memory of the future (Nietzsche, 2006). We will have to ask whether the Earth can have a 'memory of the future' that enables it to act in surprising ways.

\section{Memory and the political}

What is the political role of memory and forgetting in human society? Paul Connerton (2009) makes the point that contemporary culture is at once hypomnesic and hypermnesic. On the one hand, the structures of the political economy are organised around forgetting. With craft production replaced by mass production, and the diachrony of work replaced by synchrony of exchange value; the mass- 
produced commodity is stripped of individual acts of making in a sustained act of forgetting. The commodity form itself, as analysed by Marx, could be said to depend on organised forgetting. Similarly, as 'all that is solid melts into air', the 'memory places' that provide people with mnemonic structures which sustain cultural memory and identity are stripped away. On the other hand, despite - and in fact maybe because - of the hypomnesia of our political economy, contemporary cultural production is hypermnesic in its obsessive production and hoarding of information and signs.

In recent debates there has been an emphasis on the way that the domination of one society or one group by another often involves the destruction of memory. For example, Johannes Fabian points out how the colonisation of Africa by European powers involved the systematic erasure of the memory practices of local cultures (Fabian, 2007). Norman Klein (1998) uses Los Angeles as a proxy for capitalist spaces in general, analysing the selective way that the past is preserved or erased as urban spaces develop over time under commercial pressures. But sometimes too much memory can weigh on the present; an excess of memory can produce trauma, revenge and war (Rieff, 2016).

Jacques Derrida famously warned us that sometimes the drive to remember - to store up memories in an indestructible form - can result in the opposite effect. Because of the fragility and vulnerability of live or spontaneous memory (mneme or anamnesis), the archive tries to protect memory from destruction by incarcerating it in a memory prosthetic (Derrida, 1995: 22). But of course the hypermnesia of the archive contains within itself a vulnerability. The archive repeats, and repetition is an aspect of the death drive, of the very destruction which the archive is trying to resist. The archive works against itself and can be a form of forgetting - this is the mal d'archive, (Derrida, 1995: 14). But hypomnesia can take other forms, and for these we need to turn to Friedrich Nietzsche's reflections on the different modalities of human memory.

In Nietzsche's philosophical anthropology, the phenomenon of the human arises with the advent of the historical mode of being - of long-term, culturally mediated memory. However, wherever there is an excess of history the human ceases to be once again (Nietzsche, 2006: 128). The human thus needs both the historical and the unhistorical to be free, and becoming unhistorical involves forgetting. "It is possible to live almost without memory ... but without forgetting, it is utterly impossible to live at all' (Nietzsche, 2006: 127). Nietzsche insists that he would only serve history if it would serve life; and the form of remembering that can serve life is always an active process that includes forgetting, that he understands as a form of selective retention (Nietzsche, 1967: 57). In 'On the utility and liability of history for life', Nietzsche describes three modes of history or cultural memory: the antiquarian, deployed by those who would preserve and revere the past; the critical, for those in need of liberation; and the monumental history for those who act and strive. He insists that all three of these forms of cultural memory are selective, must serve the needs of the present. Here Nietzsche is anticipating the findings of psychological memory studies; acts of misremembering and forgetting are themselves active too, and related closely to identity and the ability to persist as a being capable of action (Schacter et al., 2003).

In his Genealogy of Morals Nietzsche went on to describe forgetting as a positive faculty of repression that acts as a 'door keeper' between the memory (the retaining of impressions) and the will, and thus as necessary for psychic health and the ability to act. He likens the person who cannot forget to a dyspeptic or constipated person, one who cannot 'have done' with anything. By contrast, for Nietzsche a healthy person, one who can forget, has a memory of the will, one that does not merely record the past but ordains the future (Nietzsche, 1967: 58; see also Deleuze, 1983: 112-3). In his explication of this Nietzsche here focuses on what he sees as the constitutive human power or right to make promises. ${ }^{4}$ Deleuze also observes that the memory proper to the human is the memory of the will, and of the future; Nietzsche's free human recalls not the past moment of making a promise (in episodic memory) but the future moment in which that promise will be fulfilled (Deleuze, 1983: 134). 


\section{How the Earth remembers and forgets}

And so back to Earth. Natural scientists frequently use 'memory' in a broadly analogical way to describe physical processes. For example, geologists talk of 'lithospheric memory', the way that events in deep time can have an enduring effect on current geological processes (e.g. Cloetingh et al., 2005); ecologists use 'ecological memory' to refer to material and informational legacies of earlier ecological disturbances that can affect the resilience of contemporary biota (e.g. Johnstone et al., 2016); and climatologists describe the way that current climate states such as temperature and humidity can exhibit longer term correlations as 'climate memory' (e.g. Koster and Suarez, 2001). What is common to all of these is the use of 'memory' to describe situations where current and near future-states depend on, or in some way correlate with, not only the immediate past but deeper temporalities. Armed with our checklist from above, can we stretch our ideas of memory further and make this more than 'mere' analogy?

Firstly, what are the modalities of planetary memory? ${ }^{5}$ How is memory stored? We can divide the modalities of planetary memory roughly into three groups. The first involves forms of energy, such as the kinetic energy of motion, the thermal energy of relative temperature, or the chemical energy stored in molecular bonds. thus the Earth itself can be said to remember the processes of its formation not least in the form of the residual heat trapped and slowly leaking out from the planet's interior. The second involves matter - here, for example, fluids can carry a memory of dissolved or suspended substances, such as moisture or anthropogenic chemicals. The third involves space: the very shape, location or arrangement of something can constitute a form of information which can act as a form of memory. All of these modalities have their own specific powers of persistence, but also of transmission and influence: motion, temperature, composition, shape and location can all be passed from object to object, substance to substance.

Secondly, given the material carriers of memory, what are its wider thermodynamic preconditions? Memory in any interesting sense has to be understood as a phenomenon that occurs on the borderline between ordered and chaotic regimes (Kauffman, 1993). On the one hand, highly ordered systems may be unable to make new memories - or may be able to lay them down but be unable to 'read' or use them to alter their behaviour. On the other hand, chaotic systems are so reactive to any stimulus that they cannot remember anything over all but the shortest timescales. It is in what Kauffman calls the 'complex regime' at the boundary between the ordered and chaotic regimes, between hypermnesis (memory turned up too far) and hypomnesis (memory turned down too far) that the powers of memory can most fully be realised (Kauffman, 1993: 174).

Thirdly, if memory is autoaffection, an aspect of the internal time of things in which they affect themselves over time, can we use this to specify more closely the kind of temporal patterns characteristic of memory processes in a dense, complex, differentiated assemblage such as the Earth? Here we can use the concept of 'noise', defined as signal produced by a stochastic process and thus containing frequencies that range continuously in value. The noise characteristic of different kinds of phenomena can be spectrally decomposed into different power spectra, named after different 'colours', by analogy with 'white noise' which, like white light, has a flat frequency spectrum.

In noise terms, hypermnesis corresponds to black noise - an absolute memory where present states totally correspond to and thus can be used to calculate past and future events. The motion of planetary bodies in the vacuum can be seen as hypermnesic in this sense, as they follow the ellipses, parabolas and hyperbolas of gravitational motion, guided by the absolute memory of reversible Newtonian mechanics. As Prigogine and Stengers put it, the planets like all objects of classical dynamics already know everything they need to know in order to move along their orbits, and can never forget it (Prigogine and Stengers, 1984, pp. 305-6). ${ }^{6}$ On the other hand, hypomnesia, extreme forgetfulness, corresponds to white noise. White noise can be produced by a memoryless process known as a 'Markov chain' - a chain of events when the probability of each possible event depends only on the immediately prior state. Information is lost and entropy increases. In fact a Markov process has two chains of memory erasure - one extending into the future and one into the past; looking at the present tells us nothing about future states - but neither does it tell us anything about 
past states (Prigogine and Stengers, 1984: 273). This form of time is thus as reversible in its hypomnesic forgetting as the black noise of planetary motion is in its hypermnesic over-remembering.

At first glance, intra-planetary memory processes look hypomnesic. In the dense media of fluid stellar and planetary compartments, and under far-from-equilibrium conditions, the perfect, reversible motion of the planets is all but impossible; inertia becomes not a form of memory as it is with planetary orbits but a source of forgetting, of dissipation, as moving entities diverge from their path in what Lucretius called the clinamen, losing not just their direction but their very motion in cascading eddies (Serres, 2000). However, planetary forgetting also forms the basis of new and very different powers of motion and memory, which break with the time symmetry shared by black and white noise. Planets - gravitationally collapsed into their own gravity well, isolated in the vacuum, and subjected to flows of energy from sun and core - are bodies where the conditions favour the creation of information-rich pockets, where correlated states and motions can arise, endure and become more elaborate (Hidalgo, 2015).

If the noise of absolute remembering is black noise, and the noise of absolute forgetting is white noise, then the noise characteristic of the complex regime of self-organisation is surely 'pink noise'. Pink noise, or $1 / f$ noise, technically defined as a signal where power is inversely proportional to the frequency of the signal, is a shape of time in which long-term correlations dominate, and is characteristic of the self-organising processes of organic life (Szendro et al., 2001), human music (Voss and Clarke, 1978) - and surely social life too.

Fourthly, what are the specific powers of memory characteristic of the different parts of the Earth? Here, I only have space for some general observations about the role of the different phases of matter - solid, liquid and gas - in planetary memory. Planets such as the Earth are made up of chemically diverse, condensed, classical baryonic matter (i.e. 'normal' atoms), existing typically at a mid-range of temperatures between the cold of space and the huge temperatures of stars, and thus able to divide themselves into complex entities and regions with different powers and properties, which are then able to enter into diverse interactions with each other. Planets are also gravitationally collapsed and differentiated, so that they form dense, approximately spherical bodies organised internally into different strata and compartments; from its solid core up to its gaseous atmosphere, the Earth is composed of regions of matter in different states, with different powers.

Fluids are inherently hypomnesic, especially in terms of memory stored as motion or shape. As Derrida warned us, spontaneous, living memory, mneme, is vulnerable - fluid memory is wiped by dissipation, friction, viscosity and the weakness of fluid molecular bonds. However, partly because of this hypomnesia, fluids are superb at creating form; liquids with moderate viscosity such as water are incessantly drawn to creating shapes such as spirals, waves, vortices, spheres and bells (Schwenk, 1965). In so far as fluids such as air have their own powers of remembering these take the form of a living, 'oral', or working memory - a memory of energy, stored in motion and intensivity, that has to be continually maintained in action or it almost literally evaporates. For example, in some latitudes, air sometimes forms itself into dissipative systems (Prigogine and Glansdorff, 1971) such as cyclones and anti-cyclones, that maintain their identity and shape over time over a number of days by exporting entropy to their surroundings.

Solids such as rock, by contrast, have 'conformational' memory - unlike fluids, they retain their shape, even when surrounding matter is removed. But here we can be more precise about the specific ways that solids such as rock remember and forget across different timescales. Where rock is elastically deformed, such as a tectonic plate under applied stress, the rock retains the memory of its original shape. The energy used to bend it is being stored in the molecular bonds. In an earthquake the plates slip past each other, the stress is removed, and the rock springs back to its original shape. What an elastically deformed rock cannot remember is previous deformations and stresses - after each earthquake, the memory is reset. Conversely, when rocks stretch beyond their elastic limit and fault, the energy is not stored in the molecular bonds but is used to change the shape of the rock. This is an example of hysteresis, or path dependency - of irreversible time. This is where lithospheric memory becomes both an archive of different deformation events, which can be read by an outside 
observer, but also consequential in that it affects the behaviour of that geological formation in the future.

Fifthly, how do planetary systems practice forms of transduction of memory? In physics, 'transduction' is used to refer to the conversion of one form of energy into another; in biology, it refers to the conversion of signals between different media. Adrian Mackenzie (2002: 25) stretches the concept further, describing transduction as 'a process whereby a disparity or difference is topologically and temporally restructured across some interface'. For our purposes, memory transduction involves the restructuring of memory processes across an interface, in such a way that the modes of becoming of both entities or substances become entangled. To speak of memory transduction is thus already to stretch the concept of memory beyond either the psychological or biological containment within the animal body, or even the more expansive definition of memory as autoaffection.

Regarding human memory, ideas of transduction involve the recognition that memory resides not just in the individual mind and its organic substrate but is also redistributed across the social body in collective memory, or even placed in artefacts and inscriptions in the inorganic realm (Clark and Chalmers, 1998). In contrast to the 'engrams' that are memories stored within the brain, Merlin Donald refers to external symbolic storage systems as involving containing 'exograms', in the form of visuosymbolic representations, oral memory and socially organised literacy, which overcome the limitations of biological memory, can be stored in a potentially unlimited range of physical media, and be accessed and retrieved through an expanded range of senses and pathways (Donald, 1991: 315). Thus the practice, for example, of placing things at the bottom of the stairs in order to remember to take them upstairs can be seen not just as an aid to memory, but as a form of memory itself - an act of delegation, in Latour's language (1992), of distributed memory. We can follow Bernard Stiegler (1998) by seeing 'mnemotechnics' as referring not just to deliberate techniques of memory, but also to the way that artefactuality and technicity in general is an exteriorisation of memory - that the equipmental assemblage of cups, stairs and pencils with which we are surrounded is part of how we remember who we are and what we know.

With the expanded notion of memory that we developed above, we can start to see that mnemotechnics or memory transduction occurs not just between humans and humans, or humans and nonhumans, but amongst nonhuman and even non-living entities. It is the general pattern of planetary evolution, of dividing and associating, that makes planetary mnemotechnics possible. Much of this is exchange between the different compartments of the Earth, which separated as the planet formed but are driven to be in close interaction by the far-from-equilibrium condition of planetary being. The Earth in its differentiated layers is a 'matryoshka doll' of alternating solid and fluid volumes. Although there are good reasons to talk of the way that planetary differentiation makes possible the relative closure (in systems terms) of the different memory systems and their modalities, it also makes possible crucial processes of transduction between them.

It is perhaps most markedly at the interfaces between the 'sensitive chaos' of fluid motion and the archival properties of solid durability that transductive processes occur in the Earth which ensure that differentiated planets become informationally complex bodies where correlated states and motions can arise, endure and become more elaborate (Hidalgo, 2015). For example, in river basins the interaction between water and rock in processes of erosion and sedimentation helps water falling on the land to remember how to travel to the ocean, generating complex fractal networks that drain in optimal ways (Rodríguez-Iturbe and Rinaldo, 1997). Similarly, the complex crust of the Earth, with its diverse minerals and concentration of metals in ores and deposits, arises from the transduction of memory processes between subterranean water's powers to dissolve and transport different elements, and rock's powers of retention.

\section{The Anthropocene as a memory event}

How does the Anthropocene as a geochronological event fit into my account of planetary memory? Let me first summarise where we have got to. I suggested that we regard memory as autoaffection - 
of the way that entities affect themselves across time; this means that specifying what kind of thing an entity is is already to specify what powers of memory it has. We have also seen that memory takes diverse forms - working in different modalities, across different timescales and allowing an entity to affect itself in very different ways. In terms of the politics of memory, we explored the complexity of the relationship between memory, forgetting and the political, seeing that one kind of forgetting - the erasure of collective memory - is a form of power over - but that other forms of forgetting can play a constitutive role in power to - the ability to become a political actor able to shape the future. Put crudely, political agency thus manifests in the space between hypomnesia and hypermnesia, between too little and too much memory.

We then turned to the more-than-human and saw that the powers of matter to organise itself also depend on finding that space between hypomnesia and hypermnesia. We saw that the different parts and subsystems of the Earth support different memory systems, each of which can be said to have their own mnemic strengths and weaknesses. For example, memories laid down in rock are like a great archive, but have the corresponding weaknesses of archived knowledge; only some of rock's memories can be recalled by the rock itself, or by other parts of the Earth, and become part of the Earth's ongoing ability to do new things. The memory of the air is kinetic memory - oral, working memory, constantly creative and inventive in the generating of form - but also has the weaknesses of that form of memory, in its inherent vulnerability to be lost. But we then saw that in the dense, differentiated body of the Earth, forms of transduction between its diverse memory systems enable it to take advantage of the diversity of its different memory systems, enabling it to become an evermore complex body, with diverse powers and potentialities.

How can this journey through ideas of planetary memory help us think about the Anthropocene? A detailed exploration of this is impossible here, but I can at least sketch out three complementary interpretations of the relationship between the Anthropocene and planetary memory - in effect, three research questions. The first is to ask how the Anthropocene involves the laying down of new memories; this indeed is the focus of the Anthropocene Working Group, which has to see even forgetting as the laying down of a trace, in terms of lithostratigraphic, chemostratigraphic and biostratigraphic signals that might be discerned in a future rock series by an imagined geologist (Williams et al., 2016). The second involves asking how the Anthropocene is potentially a scrambling of the memory systems of the Earth, not just for observers, but for the Earth itself, so that it forgets what it knows, and maybe loses the ability to make and use new memories, to learn and to develop new powers. Such a way of framing the Anthropocene can help us clarify many of our deeper ethical intuitions concerning the physical changes that the Earth is undergoing such as biodiversity loss. The third would be to ask whether what we are struggling to name at the moment is in fact the Earth also adding new memory systems, in the form of the technosphere, the evolving interconnected system of technical artefacts (Haff, 2014).

As we move through these three research questions, we should recall what Derrida wrote in 'Archive fever' (Derrida, 1995). Whether it is the very strata of the rock, or an archive created by humans in order to record Earth's memories and what it knows, the archive's very form of resistance to forgetting makes a more final forgetting possible - the hiding or destruction of the archive. The closed archive of the solid body of the Earth is now being opened but at the same time ransacked. Which kind of memory is strongest? Which will last the longest and be most consequential in the Anthropocene? When we remember the Earth, and remember for the Earth, should we remember as a mountain, as a great archive? Or as a storm, a vortex, a howl, as living memory? Which kind of memory - and which kind of forgetting - will enable the Earth to act in the way in which it needs to act at this time?

\section{Notes}

${ }^{1}$ I would like to thank Nigel Clark, Piers Foster, Andy Jarvis, Wolfgang Lucht and Adam Bobette for conversations which have greatly helped me in the ideas in this paper - though I have to take responsibility for the way that I 
have brought them together. An earlier version of this paper, 'The Anthropocene and the memory of the Earth', was presented at the colloquium The Thousand Names of Gaia: From the Anthropocene to the Age of the Earth, Rio de Janeiro, Brazil, 15-19 September 2014.

${ }^{2}$ These were the two features that Arendt sees as most constitutive of the human as a political animal: plurality, the uniqueness of humans (that 'men, not Man, live on the earth and inhabit the world'), and natality, human beings' capacity to initiate radically new things in the world (Arendt, 1958: 7).

${ }^{3}$ I am using this term in a different way to Bernard Steigler (1998), who uses 'hypermnesia' as another name for the exteriorisation or transduction of memory.

${ }^{4}$ This idea was later taken up by Hannah Arendt in her analysis of the human condition. For Arendt, the plurality of human perspectives make the results of meaningful human action - speech or gesture - inherently unpredictable and irreversible (in geophysical terms, we would say turbulent). But this inherent irreversibility and unpredictability can be tamed through specific forms of action through binding speech acts such as promising (in which the future is secured) and forgiving (in which the past is reversed) (Arendt, 1958).

${ }^{5}$ Here I am setting aside the more obvious memory modalities of arbitrary codes stored in DNA, culture and language or computational machines; these too need to be analysed as forms of planetary memory but there is not space to do that here.

${ }^{6}$ Of course as with all things planetary this is relative to a particular time scale.

\section{References}

Arendt, H., 1958. The Human Condition. University of Chicago Press, Chicago.

Bergson, H., 1959. Matter and Memory. Doubleday, New York.

Clark, A. and Chalmers, D., 1998. The extended mind. Analysis, 58(1): 7-19.

Cloetingh, S., Ziegler, P.A., Beekman, F., Andriessen, P., Matenco, L., Bada, G., Garcia-Castellanos, D., Hardebol, N., Dè Zes, P. and Sokoutis, D., 2005. Lithospheric memory, state of stress and rheology: Neotectonic controls on Europe's intraplate continental topography. Quaternary Science Reviews, 24.

Connerton, P., 2009. How Modernity Forgets. Cambridge University Press, Cambridge.

Crownshaw, R., 2014. Memory and the Anthropocene. Témoigner entre Histoire et Mémoire, 119: 175.

Crutzen, P.J. and Stoermer, E.F., 2000. The "Anthropocene". IGBP Newsletter, 41: 17-18.

Deleuze, G., 1983. Nietzsche and Philosophy. Columbia University Press, New York.

Deleuze, G., 1988. Foucault. University of Minnesota Press, Minneapolis.

Derrida, J., 1995. Archive fever: a Freudian impression. Diacritics, 25(2): 9-63.

Donald, M., 1991. Origins of the Modern Mind: Three Stages in the Evolution of Culture and Cognition. Harvard University Press, Cambridge, MA.

Fabian, J., 2007. Memory against Culture: Arguments and Reminders. Duke University Press, Durham.

Grosz, E., Yusoff, K. and Clark, N., 2017. An interview with Elizabeth Grosz: geopower, inhumanism and the biopolitical. Theory, Culture \& Society, 34(2-3): 129-146.

Haff, P.K., 2014. Technology as a geological phenomenon: implications for human well-being. In: C.N. Waters, J.A. Zalasiewicz, M. Williams, M.A. Ellis and A.M. Snelling (Editors), A stratigraphical basis for the Anthropocene? . Geological Society of London, London.

Hidalgo, C.s.A., 2015. Why Information Grows: The Evolution of Order, from Atoms to Economies. Penguin Books, London.

Husserl, E., 1991. On the Phenomenology of the Consciousness of Internal Time (1893-1917). Kluwer, Dordrecht.

Johnstone, J., F., Allen, C.D., Franklin, J.F., Frelich, L.E., Harvey, B.J., Higuera, P.E., Mack, M.C., Meentemeyer, R.K., Metz, M.R., Perry, G.L.W., Schoennagel, T. and Turner, M.G., 2016. Changing disturbance regimes, ecological memory, and forest resilience. Front. Ecol. Environ., 14(7): 369378.

Kauffman, S.A., 1993. The Origins of Order: Self-Organization and Selection in Evolution. Oxford University Press, Oxford.

Klein, N.M., 1998. The History of Forgetting: Los Angeles and the Erasure of Memory. Verso, London. 
Koster, R.D. and Suarez, M.J., 2001. Soil moisture memory in climate models. Journal of Hydrometeorology, 2(6): 558-570.

Kubler, G., 1962. The Shape of Time: Remarks on the History of Things. Yale University Press, New Haven, CN.

Latour, B., 1992. Where are the missing masses? The sociology of a few mundane artifacts. In: W.E. Bijker and J. Law (Editors), Shaping Technology/Building Society: Studies in Sociotechnical Change. MIT Press, Cambridge, MA, pp. 225-258.

Latour, B., 1993. We Have Never Been Modern. Harvester Wheatsheaf, Hemel Hempstead.

Mackenzie, A., 2002. Transductions: Bodies and Machines at Speed. Continuum, London.

Meillassoux, Q., 2008. After Finitude: an Essay on the Necessity of Contingency. Continuum, London.

Merleau-Ponty, M., 1962. Phenomonology of Perception. Humanities Press, New York.

Nietzsche, F., 2006. On the utility and liability of history for life. In: K. Ansell Pearson and D. Large (Editors), The Nietzsche Reader. Blackwell, Oxford, pp. 124-141.

Nietzsche, F.W., 1967. On the Genealogy of Morals, On the Genealogy of Morals and Ecce Homo. Vintage Books, New York, pp. 1-163.

Prigogine, I. and Glansdorff, P., 1971. Thermodynamic theory of structure, stability and fluctuations. Wiley, New York.

Prigogine, I. and Stengers, I., 1984. Order Out of Chaos: Man's New Dialogue with Nature. Bantam Books, Toronto.

Rieff, D., 2016. In Praise of Forgetting: Historical Memory and Its Ironies. Yale University Press, New Haven.

Rodríguez-Iturbe, I. and Rinaldo, A., 1997. Fractal River Basins: Chance and Self-Organization. Cambridge University Press, Cambridge.

Rothberg, M., 2017. Memory and implication at the limits of the human: a response to Nathan Snaza. Parallax, 23(4): 512-516.

Schacter, D.L., Chiao, J.Y. and Mitchell, J.P., 2003. The seven sins of memory: implications for self. Annals of the New York Academy of Sciences, 1001(1): 226-239.

Schwenk, T., 1965. Sensitive Chaos: The Creation of Flowing Forms in Water and Air. Rudolf Steiner Press, London.

Serres, M., 2000. The Birth of Physics. Clinamen Press, Manchester.

Stiegler, B., 1998. Technics and Time, 1: The Fault of Epimetheus. Stanford University Press, Stanford, CA.

Szendro, P., Vincze, G. and Szasz, A., 2001. Bio-response to white noise excitation. Electro- and Magnetobiology, 20(2): 215-229.

Voss, R.F. and Clarke, J., 1978. "1/f noise" in music: music from 1/f noise. The Journal of the Acoustical Society of America, 63(1): 258-263.

Williams, M., Zalasiewicz, J., Waters, C.N., Edgeworth, M., Bennett, C., Barnosky, A.D., Ellis, E.C., Ellis, M.A., Cearreta, A., Haff, P.K., Ivar do Sul, J.A., Leinfelder, R., McNeill, J.R., Odada, E., Oreskes, N., Revkin, A., Richter, D.d., Steffen, W., Summerhayes, C., Syvitski, J.P., Vidas, D., Wagreich, M., Wing, S.L., Wolfe, A.P. and Zhisheng, A., 2016. The Anthropocene: a conspicuous stratigraphical signal of anthropogenic changes in production and consumption across the biosphere. Earth's Future, 4(3): 34-53. 